\title{
Alignment of the Purchasing Strategy to the Business Strategy: An Empirical Study on a Harbour Cranes Company
}

\author{
Sandra Martínez ${ }^{1}$, Miguel Mediavilla ${ }^{1}$, Jenny Bäckstrand ${ }^{2}$, and Carolina Bernardos ${ }^{3}$ \\ ${ }^{1}$ GLOBOPE Research and Consulting, San Sebastián, Spain, \\ \{sandra.martinez, miguel.mediavilla\}@globope.es \\ ${ }^{2}$ School of Engineering, Jönköping University, Jönköping, Sweden \\ Jenny. Backstrandejth.hj.se \\ ${ }^{3}$ Department of Economic Analyis, University of Zaragoza \\ 472387@unizar.es
}

\begin{abstract}
The purchasing function is assuming an increasingly relevant role within companies in the last decades. This is due to a fact that purchasing strategy can contribute to develop competitive advantages. Therefore, it is important to align the purchasing strategy with the company business strategy. On the other hand, category management can be used as the basic unit of strategic purchasing analysis, which measures the competitive improvement in purchasing management. It its known that a differentiated purchasing strategy involves managing suppliers within the different categories, so that, it is considered that there should be a leadership to level category by purchasing managers to improve the company competitiveness. Hence, this paper contributes by presenting how aligned business and purchasing strategies and product categorization leads to increased competitiveness -by presenting an empirical study on a harbor cranes company.
\end{abstract}

Keywords: Purchasing function, purchasing strategy, category management, business strategy.

\section{Introduction}

In the past few decades the purchasing function has changed from a passive administrative role into a strategic function [1, 2, 3, 4] having direct responsibility for the costs of goods purchased (e.g. materials, products or services), as well as supplier management. This change has increased the impact and influence of the purchasing function to achieve competitive advantages for the business, as other business functions do. Moreover, this development is logical, as the sourced components represent a large and growing percentage of the total cost of a product, as well as these components have a crucial importance depending on its quality and performance [5].

The purchasing strategy is the process of planning, implementing, evaluating and controlling the strategic and operative purchasing decisions. These decisions lead all 
activities of the purchasing function toward opportunities that are consistent with the capabilities of the company in order to achieve the long-term objectives [6]. Hence, in order to get competitive advantages, the purchasing strategy must be aligned with the overall strategy of the company. Furthermore, different purchasing strategies are needed for different types of purchased items [7, 8].

The literature shows that in this era of purchasing it is necessary to provide solutions to different challenges, risks and characteristics. Neverthelessone of the most important challenges is to align the purchasing strategy with the business strategy, .In order to achieve a better alignment, one key step is to define the appropriate purchasing strategy for each purchasing category in order to achieve the goal defined within the business strategy [6], [9, 10, 11, 12].

Therefore, the research question would be: How can the alignment of purchasing strategy with business strategy and product categorization improve the competitiveness of a company?

In order to give an answer this question, this paper will illustrate through an empirical study how aligned strategies lead to increased competitiveness. First, the paper presents a brief literature review; then the adopted research methodological approach is presented. Then, a case study carried out on a harbor cranes company is explained. Finally, the paper concludes by highlighting the contribution of the research.

\section{Literature Review}

\section{Strategic Alignment}

The purchasing function is assuming an increasingly relevant role within companies. This is due to a fact that purchasing strategy can contribute to get competitive advantages. Therefore, it is important to align the purchasing strategy with the business strategy of the company.

Generally, business strategy is concerned with developing distinct competences and competitive advantages [13]. One approach to business-level strategy is the competitive strategies, introduced by Porter [14], that drive an actor to compete as cost leader, differentiator, or a focused provider.

For manufacturing actors, the competitive business strategy is translated into competitive priorities and operationalized through functional strategies $[15,16,17]$. According to previous research, purchasing strategy also requires the identification of competitive priorities [16], [18] in order to support business strategy. However, different purchasing strategies are needed for different types of purchased items. Additionally alternative ways of categorizing or classifying items and/or suppliers is necessary.

Necessities for a competitive purchasing strategy configuration are external resources, location, suppliers network design, purchasing organization (from process and functional perspectives) and standardization and improvement of the purchasing and procurement processes. Additionally the globalization necessarily affect the purchasing function, forcing it to be global too [19]. Van Weele [2] defined global purchasing as "the activity for searching and obtaining goods, services and other 
resources on a possible worldwide scale, to comply with the needs of the company and with a view to continuing and enhancing the current competitive position of the company". It includes all phases of the purchasing process, starting even before the definition of the specification list, through supplier selection and buying, up to the follow-up and evaluation phase. Moreover, global purchasing management is one of the first steps to define and design a global supply chain [20].

\section{Category Management}

To define a category strategy it is advisable to have systematic classifications [21] to help defining and visualizing the different categories. One of the most commonly used tools for categorization was developed by Kraljic [7], who proposed a matrix that classifies items into categories according to their profit impact and supply risk. This matrix has become the standard in models of purchasing categories [4], [22].

In the early 90s in the UK new principles of management throughout the supply chain was developed, the so called "Efficient Consumer Response" (ECR). Its best known process, Category Management (CM) [23, 24], is defined as 'a process that involves managing product categories as business units and customizing them on a store-by-store basis to satisfy customer needs' [8] and shifted the focus from brand management approach to a category management approach [25]. Later, CM was also adapted to categorize purchased items [26].

According to Mediavilla et al. [27] and Errasti [5], proper category management requires to:

1. Categorize items.

2. Set achievable goals within the business strategy.

3. Prioritize the purchasing categories.

4. Define strategic objectives of purchasing and consequently establish improvement projects and their deployment. These targets should be aligned with the business strategy.

5. Set management indicators for each project phases.

6. Ensure lasting results.

Therefore this CM can be used as the basic unit of strategic analysis, which measures the competitive improvement on purchasing management [4], [23, 24].

A differentiated purchasing strategy then involves managing the suppliers within the different categories. According to some authors [2], [4] it is considered that there should be a leadership by purchasing managers per category to improve the competitiveness of the company.

\section{$3 \quad$ Research Methodology}

The research is based on a literature review and a case study following the constructive research methodology. Constructive research is an approach that aims to produce solutions to explicit problems and is closely related to the concept of innovative 
constructivism [28]. This approach develops an innovative solution, which is theoretically grounded, to a relevant practical problem. An essential component of constructive research is the generation of new learning and knowledge in the process of constructing the solution [29]. The case study as such is exploratory in nature. Two of the researchers have been actively involved in the project transition of the case company. Thus, facets of action research have also been deployed. In action research both researchers and clients are actively engaged in solving a client-initiated project dealing with a certain business problem [30,31,32]. The company selected for the case faced the challenge of aligning its purchasing strategy to a recently changed business strategy, providing an interesting case for academics.

The main data collection and observation period lasted for 5 months during 2013 and consisted of meetings, interviews and company internal documentation. The researchers attended meetings once a week with the Purchasing Manager, CEO, Chief Engineer, Supply Chain Manager, Quality Manager and Sales Manager. The first phase of the case research included meetings and interviews that focused on understanding the harbor cranes industry and the company specific portfolio of products. During the second phase, researchers, together with Purchasing and Quality Manager, mapped the main processes within procurement function. . Finally, the third phase focused on developing and deploying new strategy of purchasing management based on Mediavilla et al. [8] and Errasti [5].

\section{Case Research}

The case company is a Spanish provider of integral solutions for container terminals, i.e that the company designs, manufactures, transports and erects container-handling cranes. Moreover, the case company has also its own software and hardware to optimize terminal management (terminal automation). The case company is the regional supplier for Europe, Mediterranean, North and South Atlantic side of the Americas and this company is part of an international corporation.

In order to develop and deploy a new purchasing strategy, to the first step was to push a proper category management by:

1. Splitting the products on purchasing categories.

2. Defining the main contribution of each given purchasing category to the business strategy (E.g. competitive advantage on costs or lead-time). This is the so-called purchasing strategy per category. [5][8]

3. Prioritization of levers per category, seeking levers which could reinforce the given competitive advantage

4. Deployment of purchasing strategies per category by applying the selected levers. The prioritization could be based on the potential competitive improvements (E.g. saving or qualitative impact) and implementation effort.

5. Establishment management indicators: potential cost savings per crane.

6. Control system to review achieved results and strategy coherence along the time. 
The following is an example of how the category management was carried out for a specific purchasing category in the case company.

1. The analyzed product was divided on in 42 purchasing categories. However, in this case research the focus will be on one category, called 'mechanical elements' which is composed by products such as sheaves. This category could be manufactured by a large number of suppliers, which decreases the possible supply risk but will not optimize the cost if the company is not able to create the appropriate competition. Moreover, this category has a medium profit impact. Therefore, according Kraljic's matrix [7] this category is a leverage item (see Figure 1).

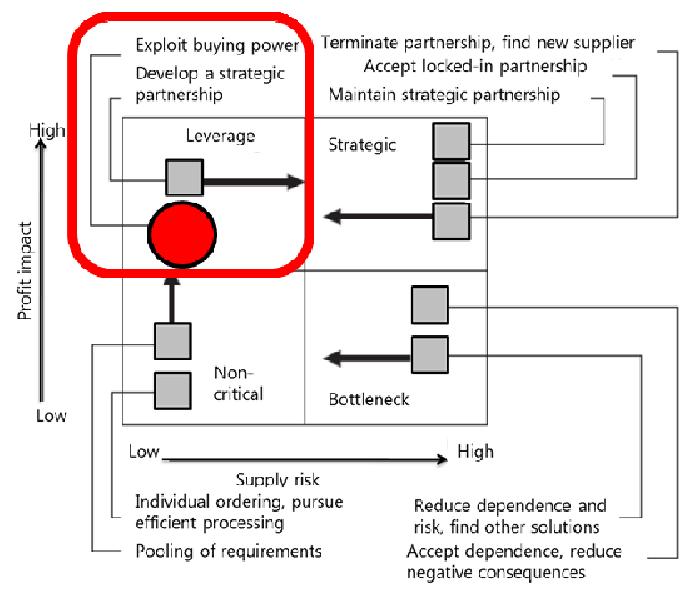

Fig. 1. Purchasing strategies for all portfolio quadrants, based on Kraljic's matrix [7], [33]

2. The main contribution to the business strategy that the category "mechanical elements" has is to improve the purchasing cost (i.e. the purchasing strategy is to reduce costs on this category). Therefore, the selected levers (i.e. how to achieve the purchasing strategy) were to introduce new suppliers and to standardize the components. Taking into account the risk/challenges and purchasing power matrix (figure 2) [5, 33], The recommended purchasing policy is to exploit purchasing power by increasing the competition between different suppliers, pushing the purchasing strategy of reducing costs. Likewise, it is also suggested to establish supplier relation case by case in order to exploit the purchasing power [5] (see Figure 2).

3. The analyzed category, according to the prioritization, belongs to the first wave of implementation according to Errasti [5], meaning that the ease of implementation is medium or high and the potential savings are medium or high too (see Figure 3). 


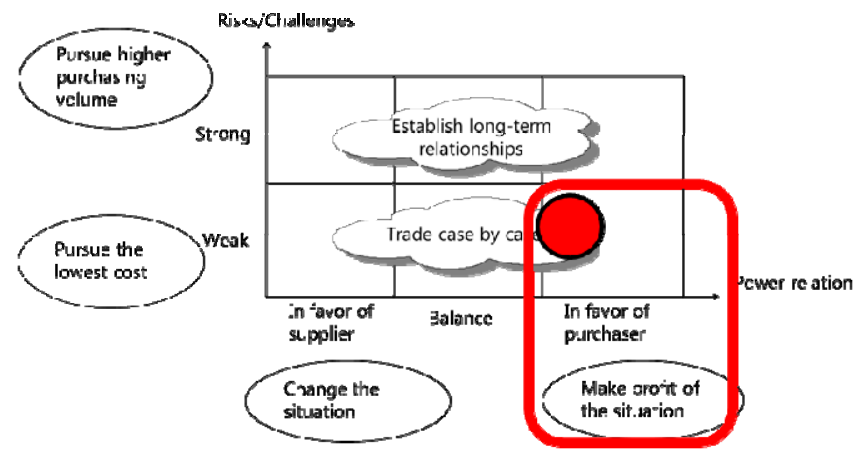

Fig. 2. Risk/challenges and power relation matrix, based on Errasti [5]

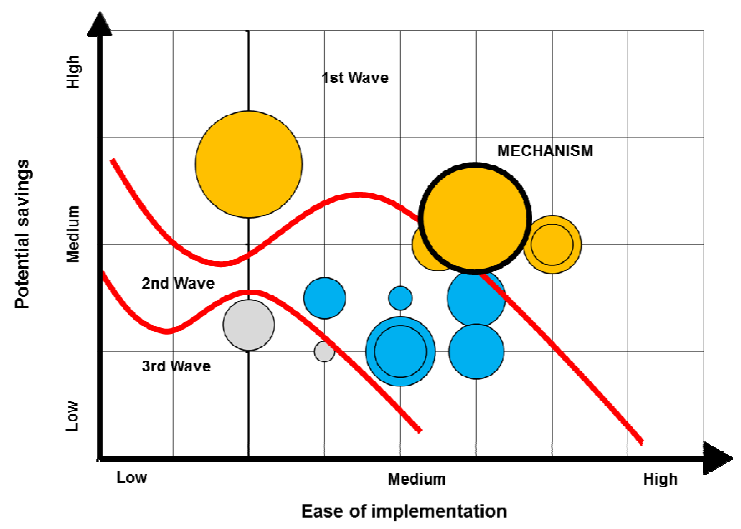

Fig. 3. Potential savings and implementation difficulties for different purchasing categories, based on Errasti [5]

4. The target was to have three new suppliers and to eliminate the current supplier due to quality problems and non-compliance with delivery dates. The company executed supplier scouting actively.

5. As a result of the strategy implementation, the supplier basis was changed and a cost reduction of approx. 50\% was achieved. That situation is totally aligned to the purchasing strategy as well as to the contribution that the category made to the business strategy.

6. Currently, the company continues working to strengthen relations and establish long-term agreements with the new suppliers.

\section{Result}

Two of the three suppliers were located in a low cost country and the third one was located in Spain. The Spanish supplier was a supplier totally oriented to short delivery times and for unexpected situations. 


\section{Contribution}

The case research shows that the use of the category management (i.e. to categorize items in purchasing categories, set purchasing strategic objectives, prioritize the purchasing categories according to the potential savings and implementation difficulties, define and deploy improvement projects, set management indicators and ensure lasting results) and the alignment of the purchasing strategy with business strategy allow to improve company competitiveness.

\section{References}

1. Ellram, L.M., Carr, A.: Strategic purchasing: a history and review of the literature. Journal of Supply Chain Management 30(1), 9-19 (1994)

2. Van Weele, A.J.: Purchasing and supply chain management: Analysis, strategy, planning and practice. Cengage Learning EMEA (2005)

3. Alinaghian, L.S., Aghadasi, M.: Proposing a model for purchasing system transformation, Glasgow, Scotland. Paper presented at the EurOMA 16th Conference (2006)

4. Monczka, R., Handfield, R., Giunipero, L., Patterson, J.: Purchasing and supply chain management, 4th edn. Cengage Learning, USA (2009)

5. Errasti, A.: Gestión de compras en la empresa. Ediciones Pirámide (Grupo Anaya), Madrid, España (2012)

6. Carr, A.S., Smeltzer, L.R.: An empirically based operational definition of strategic purchasing. European Journal of Purchasing and Supply Management 3(4), 199-207 (1997)

7. Kraljic, P.: Purchasing must become supply management. Harvard Business Review 61(5), 109-117 (1983)

8. Nielsen Marketing Research.: Category management - Positioning your organization to win. American Marketing Association, NTC Business books (1992)

9. Lindblom, A., Olkkonen, R., Ollila, P., Hyvönen, S.: Suppliers' roles in category management: a study of supplier-retailer relationships in Finland and Sweden. Industrial Marketing Management 38(8), 1006-1013 (2009)

10. Slack, N., Lewis, M.: Operations strategy. Financial Times/Prentice Hall (2002)

11. Carter, J.R., Narasimhan, R.: Is purchasing really strategic? International Journal of Purchasing and Materials Management 32(1), 20-28 (1996)

12. Bäckstrand, J.: A Method for Customer-driven Purchasing - Aligning Supplier Interaction and Customer-driven Manufacturing [Doctoral dissertation]. Jönköping University, Jönköping (2012)

13. Andrews, K.R.: The Concept of Strategy. Irwing Publishing, Homewood (1984)

14. Porter, M.E.: Competitive Strategy: Techniques for Analyzing Industries and Competitors. Free Press, New York (1980)

15. Ward, P.T., McCreery, J.K., Ritzman, L.P., Sharma, D.: Competitive Priorities in Operations Management. Decision Sciences 29(4), 1035-1046 (1998)

16. Krause, D.R., Pagell, M., Curkovic, S.: Toward a measure of competitive priorities for purchasing. Journal of Operations Management 19(4), 497-512 (2001)

17. Kroes, J.R., Ghosh, S.: Outsourcing congruence with competitive priorities: Impact on supply chain and firm performance. Journal of Operations Management 28(2), 124-143 (2010) 
18. Watts, C.A., Kim, K.Y., Hahn, C.K.: Linking purchasing to corporate competitive strategy. International Journal of Purchasing and Materials Management 28(4), 2-8 (1992)

19. Martínez, S.: Framework for configuring production and logistics networks of SMEs and SBUs within an internationalization process, Dissertation, Tecnun, University of Navarra, San Sebastián, Spain (2013)

20. Leenders, M., Fearon, H.E., Flynn, A.E., Johnson, P.F.: Purchasing and Supply Management. McGraw Hill/Irwin, New York (2002)

21. Lilliecreutz, J., Ydreskog, L.: Supplier classification as an enabler for a differentiated purchasing strategy. Best Practice Procurement: Public and Private Sector Perspective 8, 73$81(2001)$

22. Gelderman, C.J., Van Weele, A.J.: Purchasing portfolio models: a critique and update. Journal of Supply Chain Management 41(3), 19-28 (2005)

23. Gruen, T.W., Shah, R.H.: Determinants and outcomes of plan objectivity and implementation in category management relationships. Journal of Retailing 76(4), 483-510 (2000)

24. Dewsnap, B., Hart, C.: Category management: a new approach for fashion marketing? European Journal of Marketing 38(7), 809-834 (2004)

25. Dussart, C.: Category management: Strengths, limits and developments. European Management Journal 16(1), 50-62 (1998)

26. O'Brien, J.: Category Management in Purchasing: A strategic approach to maximize business profitability. Kogan, London (2009)

27. Mediavilla, M., Zubizarreta, X., Errasti, A., Chackelson, C.: Logística Sanitaria: Retos y Nuevas Tendencias, World-Class Hospital Logistics. Ulma Handling Systems and GLOBOPE Research \& Consulting, Spain (2014)

28. Meredith, J.: Theory building through conceptual methods. International Journal of Operations and Production Management 13(5), 3-11 (1993)

29. Mendibil, K., Macbryde, J.C.: Designing effective team-based performance measurement systems: an integrated approach. Production Planning and Control 16(2), 208-225 (2005)

30. Westbrook, R.: Action Research: A new paradigm for research in production and operations management. International Journal of Operations and Production Management 15(12), 6-20 (1995)

31. Rowley, J.: Using Case Studies in Research. Management Research News 25(1) (2002)

32. Voss, C., Tsikriktsis, N., Frohlich, M.: Case Research in operations management. International Journal of Operations and Production Management 22(2), 195-219 (2002)

33. Gelderman, C.J., Van Weele, A.J.: Handling measurement issues and strategic directions in Kraljic's purchasing portfolio model. Journal of Purchasing and Supply Management 9(5-6), 207-216 (2003) 